\title{
Tunnel and clip endoscopic submucosal dissection of a pharyngeal superficial squamous cell carcinoma detected with narrow-band imaging
}

Patients with squamous cell carcinoma (SCC) of the esophagus must be screened for synchronous and metachronous lesions of the head and neck during surveillance. Screening by head and neck surgeons is performed using high definition resolution (HDR) endoscopy and narrow-band imaging (NBI), which aid considerably in the detection of superficial lesions.

Endoscopic submucosal dissection (ESD) of superficial head and neck carcinomas is feasible and allows accurate pathological analysis to confirm its efficiency, in contrast to the traditional destructive therapy usually performed by otorhinolaryngology surgeons. However, ESD is particularly challenging in this location $[1,2]$ because of the narrow lumen and the difficulty of handling a scope in close proximity to the dental line. A countertraction strategy [3] has recently been reported as a technical help for this location.

Here we report a successful case of ESD for a superficial SCC of the pharynx. The lesion was diagnosed using NBI during ESD for an SCC of the esophagus ( $\vee$ Fig. 1). NBI allows clear identification of abnormalities of vascular and mucosal patterns. The margins were delineated before resection using NBI chromoendoscopy, dual focus, and Lugol vital coloration. ESD was performed by the tunnel and clip method [4] using a dual knife and with injection of a glycerol solution allowing a constant exposure of the submucosal space, which facilitated the procedure in this challenging location ( $\triangleright$ Fig. 2 and $>$ Fig. 3 ; $>$ Video 1). The patient was extubated 24 hours after ESD to avoid immediate post-ESD pharyngeal edema. Pathological analysis showed an in situ SCC with tumor-free deep and lateral margins.

HDR endoscopy, NBI, and dual focus are useful tools that permit the detection of very early pharyngeal SCC. Flexible endoscopy can be used to accurately ana-

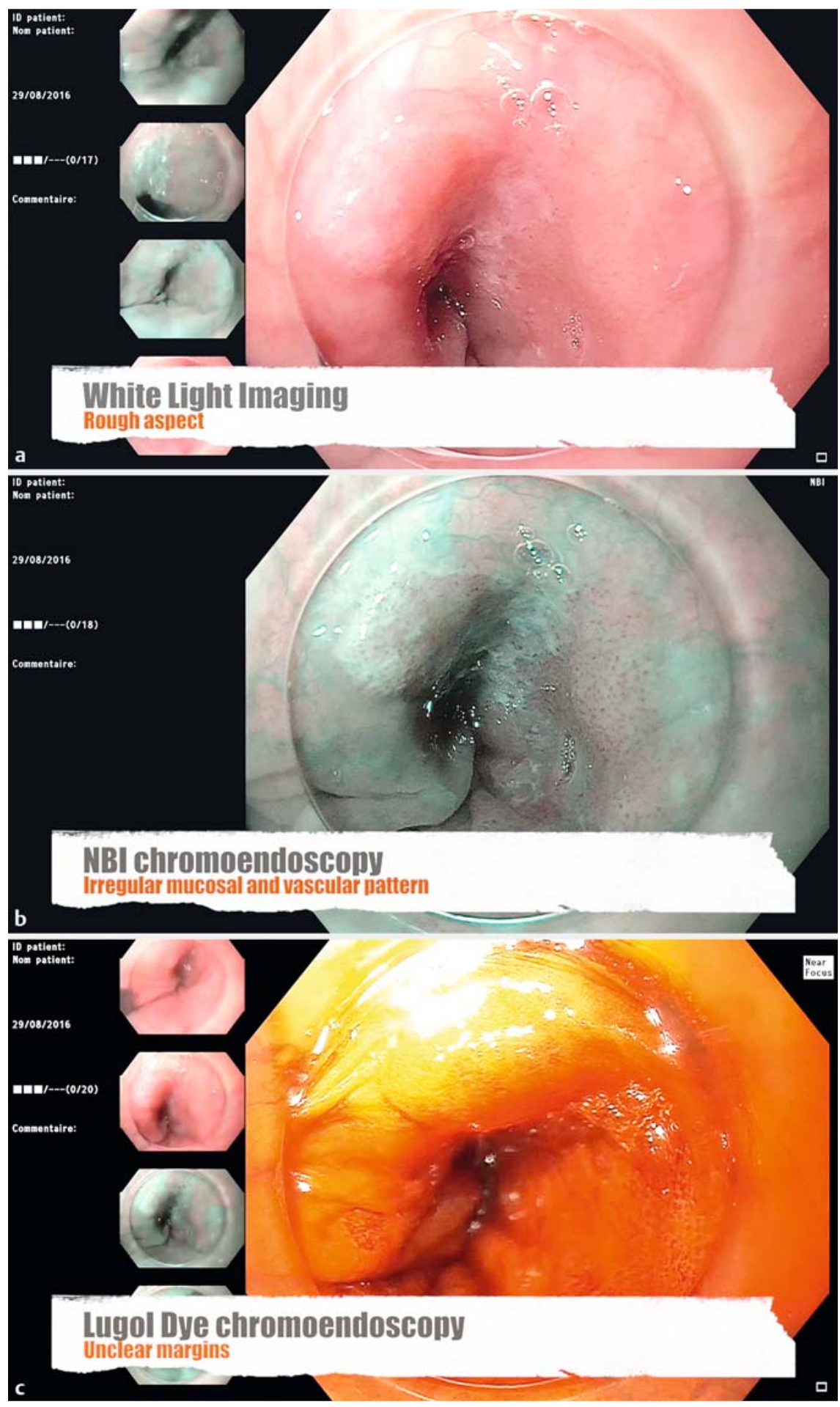

- Fig. 1 A superficial lesion in the pharynx is visualized: a on white-light imaging; $\mathbf{b}$ on narrow-band imaging (NBI); c using Lugol dye. 

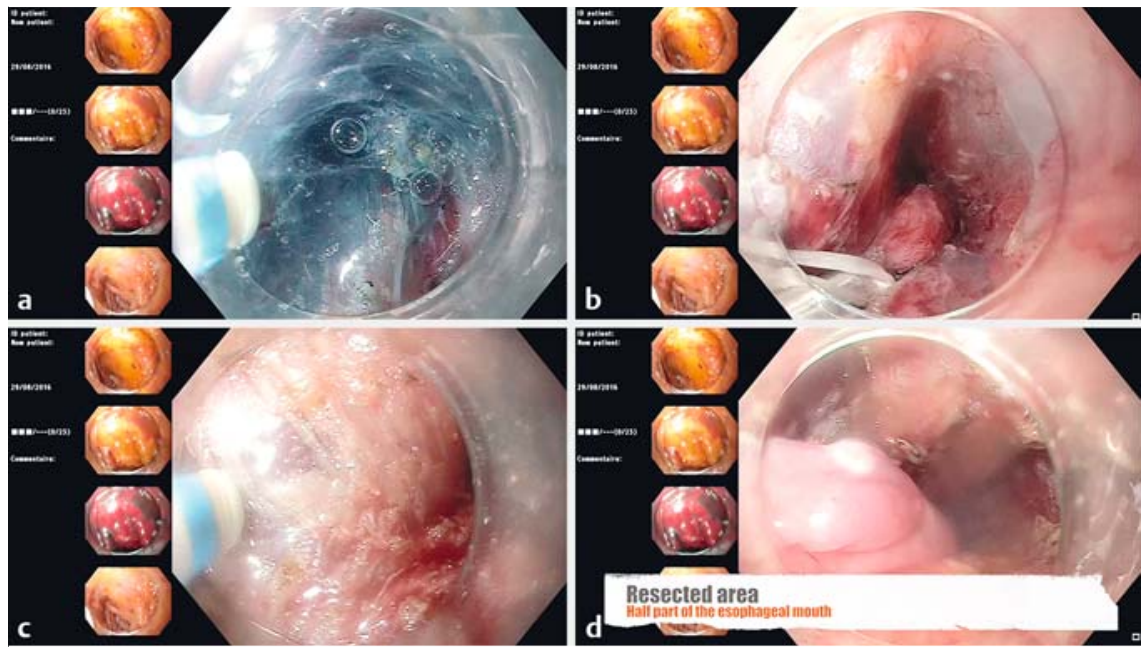

- Fig. 2 Views during endoscopic submucosal dissection (ESD) of the pharyngeal lesion showing: a creation of the tunnel; $\mathbf{b}$ clip countertraction at the end of the tunnel; $\mathbf{c}$ ESD of the lateral edge of the tunnel; $\mathbf{d}$ the area following resection.

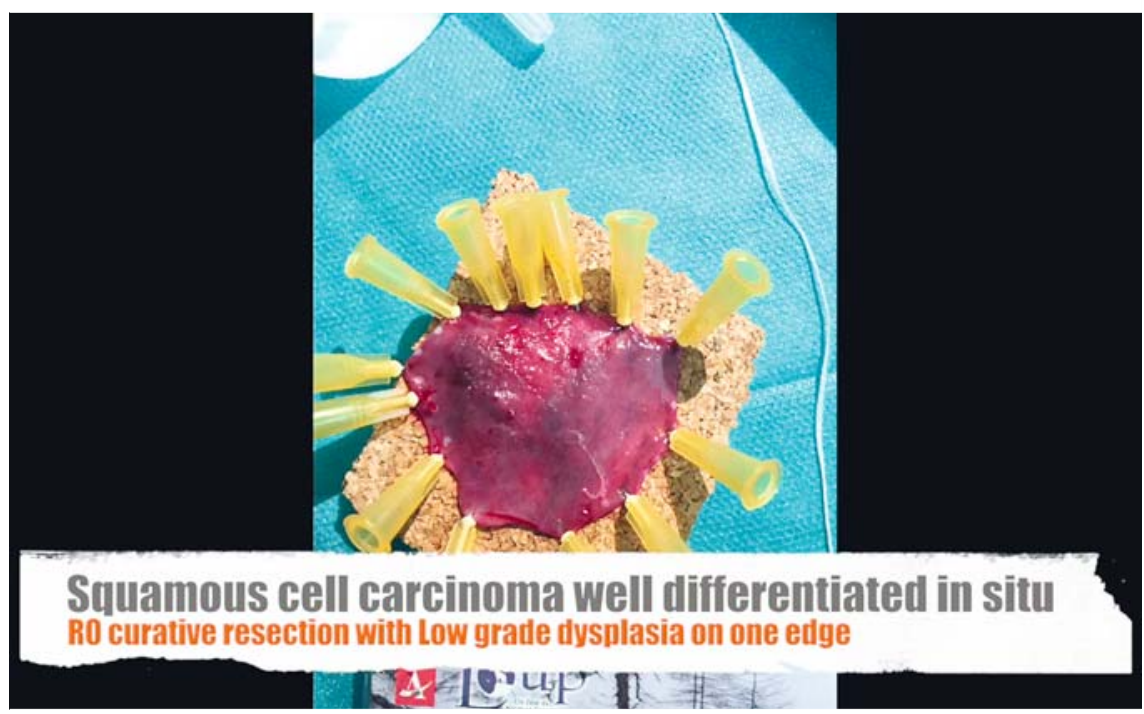

- Fig.3 Macroscopic appearance of the resected specimen.
The Authors

Jérémie Jacques ${ }^{1}$, Jérôme Rivory ${ }^{2}$, Vincent Lépilliez ${ }^{3}$, Leslie Rinaldi ${ }^{4}$, Jean-Christophe Saurin ${ }^{2}$, Thierry Ponchon ${ }^{2,5}$, Mathieu Pioche ${ }^{2,5}$

1 Gastroenterology and digestive endoscopy, CHU Dupuytren, Limoges, France

2 Digestive endoscopy unit, Gastroenterology service, Pavillon H, Hôpital Edouard Herriot, Hospices Civils de Lyon, Lyon, France

3 Gastroenterology and digestive endoscopy, Hôpital privé Mermoz, Lyon France

4 Gastroenterology and digestive endoscopy, CHU Saint-Etienne, St Etienne, France

5 INSERM U1032, LabTau, Lyon France

\section{Corresponding author}

\section{Jérémie Jacques, MD}

Service d'hépato-gastro-entérologie, $\mathrm{CHU}$

Dupuytren, 87042 Limoges, France

Fax: +33-5-55058733

jeremiejacques@gmail.com lyze this area and increase the detection of treatable lesions in high risk patients. While ESD of the pharynx is technically challenging, it is feasible; the tunnel and clip strategy facilitates the procedure and enables a conservative and curative resection.

Endoscopy_UCTN_Code_TTT_1AO_2AC

\section{Competing interests}

\section{None}

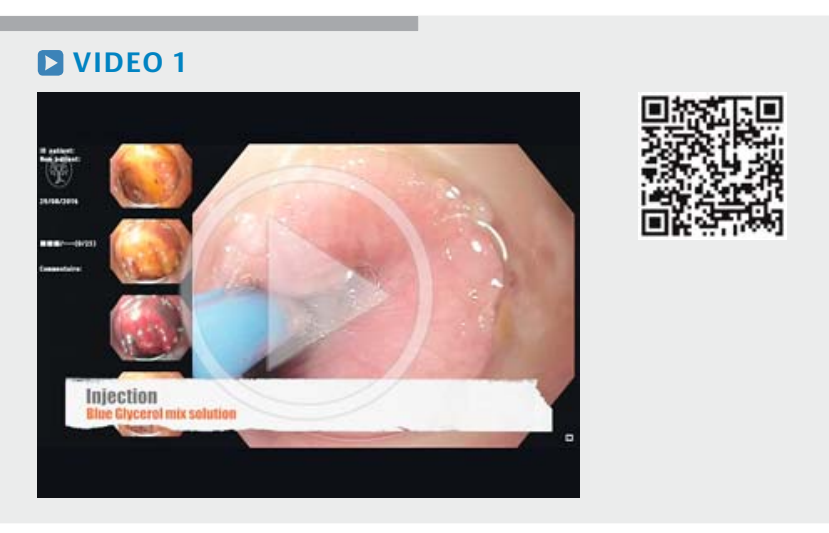

- Video 1: Endoscopic submucosal dissection (ESD) being performed on a pharyngeal superficial squamous cell carcinoma using the tunnel and clip technique. 


\section{References}

[1] Okada K, Tsuchida T, Ishiyama A et al. Endoscopic mucosal resection and endoscopic submucosal dissection for en bloc resection of superficial pharyngeal carcinomas. Endoscopy 2012; 44: 556 - 564

[2] Hanaoka N, Ishihara R, Takeuchi Y et al. Endoscopic submucosal dissection as minimally invasive treatment for superficial pharyngeal cancer: a phase II study (with video). Gastrointest Endosc 2015; 82: $1002-1008$
[3] Minami H, Tabuchi M, Matsushima K et al. Endoscopic submucosal dissection of the pharyngeal region using anchored hemoclip with surgical thread: A novel method. Endosc Int Open 2016; 4: E828 - E831

[4] Jacques J, Geyl S, Carrier P et al. A combination of the clip-with-line method and the tunnel technique during esophageal endoscopic submucosal dissection: a technical solution? Endoscopy 2015; 47 (Suppl. 01): E307-E308

\section{Bibliography}

DOI http://dx.doi.org/10.1055/s-0042-122142

Endoscopy 2017; 49: E48-E50

(c) Georg Thieme Verlag KG

Stuttgart · New York

ISSN 0013-726X 